\title{
Antimicrobial Activity of Seven Essential Oils From Iranian Aromatic Plants Against Common Causes of Oral Infections
}

\author{
Kamiar Zomorodian ${ }^{1}$; Pooria Ghadiri ${ }^{2}$; Mohammad Jamal Saharkhiz ${ }^{3}$; Mohammad \\ Reza Moein ${ }^{4}$; Peiman Mehriar ${ }^{5,{ }^{*}}$; Farideh Bahrani ${ }^{6}$; Tahereh Golzar ${ }^{2}$; Keyvan Pakshir ${ }^{7}$; \\ Mohammad Mehdi Fani ${ }^{8}$ \\ ${ }_{1}^{1}$ Basic Sciences in Infectious Disease Research Center, School of Medicine, Shiraz University of Medical Sciences, Shiraz, IR Iran \\ ${ }_{3}^{2}$ Student Research Committee, School of Medicine, Shiraz University of Medical Sciences, Shiraz, IR Iran \\ ${ }^{3}$ Department of Horticultural Sciences, Faculty of Agriculture, Shiraz University, Shiraz, IR Iran \\ ${ }_{5}^{4}$ Department of Pharmacognos, Pharmaceutical Sciences Research Center, Faculty of Pharmacy, Shiraz University of Medical Sciences, Shiraz, IR Iran \\ ${ }_{6}^{5}$ Florida Institute for Advanced Dental Education, Miami, Florida, USA \\ ${ }_{7}^{6}$ Department of Prosthodontics, School of Dentistry, Shiraz University of Medical Sciences, Shiraz, IR Iran \\ 7 Department of Medical Mycology and Parasitology, School of Medicine, Shiraz University of Medical Sciences, Shiraz, IR Iran \\ 8 Department of Oral Medicine, School of Dentistry, Shiraz University of Medical Sciences, Shiraz, IR Iran \\ *Corresponding author: Peiman Mehriar, Florida Institute for Advanced Dental Education, Miami, Florida, USA. Tel: +1-3106503034, E-mail: mehriarp@gmail.com
}

Received: January 21, 2014; Revised: April 26, 2014; Accepted: September 22, 2014

\begin{abstract}
Background: Over the past two decades, there has been a growing trend in using oral hygienic products originating from natural resources such as essential oils (EOs) and plant extracts. Seven aromatic plants used in this study are among popular traditional Iranian medicinal plants with potential application in modern medicine as anti-oral infectious diseases.

Objectives: This study was conducted to determine the chemical composition and antimicrobial activities of essential oils from seven medicinal plants against pathogens causing oral infections.

Materials and Methods: The chemical compositions of EOs distilled from seven plants were analyzed by gas chromatography/mass spectrometry (GC/MS). These plants included Satureja khuzestanica, S. bachtiarica, Ocimum sanctum, Artemisia sieberi, Zataria multiflora, Carum copticum and Oliveria decumbens. The antimicrobial activity of the essential oils was evaluated by broth micro-dilution in 96 well plates as recommended by the Clinical and Laboratory Standards Institute (CLSI) methods.

Results: The tested EOs inhibited the growth of examined oral pathogens at concentrations of $0.015-16 \mu \mathrm{L} / \mathrm{mL}$. Among the examined oral pathogens, Enterococcus faecalis had the highest Minimum Inhibitory Concentrations (MICs) and Minimum Microbicidal Concentrations (MMCs). Of the examined EOs, S. khuzestanica,Z. multiflora and S. bachtiarica, showed the highest antimicrobial activities, respectively, while Artemisia sieberi exhibited the lowest antimicrobial activity.

Conclusions: The excellent antimicrobial activities of the tested EOs might be due to their major phenolic or alcoholic monoterpenes with known antimicrobial activities. Hence, these EOs can be possibly used as an antimicrobial agent in treatment and control of oral pathogens.
\end{abstract}

Keywords:Essential Oil; infections; Medicinal Plants

\section{Background}

Dental caries is one of the main global public health problems. Based on a recent systematic analysis, oral conditions affected about 3.9 billion people worldwide and untreated caries in permanent teeth was the most prevalent condition with "a global prevalence of 35\% for all ages combined" (1). Accumulation of microbial plaque on dental surfaces is the first step of dental caries and periodontal diseases. These microbial plaques composed of native oral flora and cariogenic bacteria. The dental caries is then progressed by further destruction of teeth by acids produced by these bacteria (2). About twenty-five species of streptococci live in the oral cavity. Of these, oral streptococci such as Streptococcus mutants and S. sobrinus have direct association with tooth decay (3), while others such as $S$. sanguis and S. salivarius are less harmful and considered as normal microbial population of the oral cavity. Staphylococcus aureus is another Gram-positive cocci responsible for oral infections $(4,5)$. This species can be isolated from oral cavity of specific groups such as elderly and children $(6,7)$. Enterococcus faecalis is another Gram-positive cocci commonly isolated from endodontic infections $(8,9)$.

Yeasts including Candida species are also found in oral cavity as normal flora. Under certain circumstances such as avitaminosis, using broad spectrum antibiotics and immunosuppressive agents, they might colonize and adhere to soft and hard tissue surfaces such as dentures and form a biofilm (10). Proper oral hygiene and using

Copyright (C) 2015, Ahvaz Jundishapur University of Medical Sciences. This is an open-access article distributed under the terms of the Creative Commons Attribution-NonCommercial 4.0 International License (http://creativecommons.org/licenses/by-nc/4.0/) which permits copy and redistribute the material just in noncommercial usages, provided the original work is properly cited. 
oral mouthwashes with antimicrobial activity are considered as the main approaches in prevention of oral infections. Within the past two decades, emergence of resistance to various antimicrobial compounds has accelerated dramatically. Of these, methicillin-resistant $S$. aureus (MRSA), vancomycin-resistant Enterococcus (VRE) species and azole-resistant Candida species are among the main pathogens responsible for oral infections (11-13). On the other hand, most of these synthetic antimicrobial products have some adverse effects, which make them less popular.

An alternative approach to overcome these issues might be using natural antimicrobial products and phytochemicals. The Middle East has unique niches for medicinal plants, which have been used for treating diseases and infections for thousands of years in traditional medicine. It has been shown previously that plants and their aromatic products have potential antimicrobial activities (14). Essential oils distilled from these aromatic plants have known medicinal properties and widely used to treat a variety of diseases (Table 1). As mentioned in Table 1, these EOs are rich in terpenoid compounds in particular monoterpenes with known antimicrobial properties (15). The previous studies demonstrated the successful usage of essential oil (EO) based mouthwashes in preventing and controlling formation of plaque and gingivitis as well as reducing bad breath and odor-causing bacteria (16).

\section{Objectives}

In the previous studies, the EOs distilled from seven local medicinal plants of southern parts of Iran were prepared and their main constituents were identified by gas chromatography/mass spectrometry (Table 1). Concern- ing the emergence of resistance to antibiotics in the past decades, their unavoidable adverse effects and regarding the global tendency towards using natural products and phytochemicals in medicine, the present study was conducted to evaluate antimicrobial activity of the seven common EOs, as listed in Table 1, against the common causes of oral infections.

\section{Materials and Methods}

\subsection{Plant Materials}

The areas of plant collection were reported in the Table 1. Salvia mirzayanii was deposited at the Herbarium of Medical Science of Department of Pharmacognosy, Faculty of Pharmacy, Shiraz University of Medical Sciences, Iran (Voucher No. 663). The Satureja bachtiarica was deposited at the Herbarium of Medicinal Plants and Drugs Research Institute (MPH), Shahid Beheshti University, Tehran, Iran (Voucher No.MPH-1577). The other plants were deposited at the Herbarium of Faculty of Agriculture, Shiraz University, Shiraz, Iran with voucher numbers of SUHA-111 for Artemisia sieberi, and SUHA-110 for Oliveria decumbens, as well as at Herbarium of Shiraz University, Shiraz, Iran with voucher numbers of SUH-24989 for Ocimum sanctum, SUH-24985 for Carum copticum and SUH-24985 for Zataria multiflora.

\subsection{Essential Oil Extraction}

The aerial parts of the mentioned medicinal plants were harvested at proper growth stage and then airdried. EOs were prepared by hydrodistillation using a glass Clevenger-type apparatus according to the method

\begin{tabular}{|c|c|c|c|c|c|}
\hline No. & Plant Name & Collection Area & Major Components & Biological Activities & References \\
\hline $\mathbf{1}$ & $\begin{array}{c}\text { Satureja } \\
\text { khuzestanica }\end{array}$ & $\begin{array}{l}\text { Mazhin, Lorestan, } \\
\text { Iran }\end{array}$ & Carvacrol (87.7\%) & $\begin{array}{l}\text { Antifungal and antibacterial activities, Treatment } \\
\text { of common cold and bronchitis }\end{array}$ & (17) \\
\hline 2 & $\begin{array}{c}\text { Satureja } \\
\text { bachtiarica }\end{array}$ & $\begin{array}{l}\text { Semirom, Isfahan, } \\
\text { Iran }\end{array}$ & $\begin{array}{l}\text { Caryophyllene oxide } \\
\text { (17.0\%), Thymol (28.0\%), } \\
\text { Carvacrol (13.2\%) }\end{array}$ & & \\
\hline 3 & $\begin{array}{l}\text { Ocimum } \\
\text { sanctum }\end{array}$ & $\begin{array}{l}\text { Borazjan, Bushehr, } \\
\text { Iran }\end{array}$ & $\begin{array}{l}\text { 1,8-Cineole (20.78\%), } \\
\beta \text {-bisabolene(20.99), Euge- } \\
\text { nol (15.70\%), }\end{array}$ & $\begin{array}{l}\text { anti-oxidative,antibacterial, antifungal, antima- } \\
\text { laria, antihelmintic, antidiabetic, treatment of } \\
\text { hypertension and skin disease }\end{array}$ & (18) \\
\hline 4 & $\begin{array}{l}\text { Artemisia } \\
\text { sieberi }\end{array}$ & Fasa, Fars, Iran & $\begin{array}{c}\text { 1,8-cineole (21.1\%), Camphor } \\
\text { (16.53\%), } \alpha \text {-thujone (13.08\%) }\end{array}$ & $\begin{array}{l}\text { antidiabetic,antiviral,anti- } \\
\text { spasmolytic,vermicide,poison antidote and } \\
\text { antimicrobial effects, Antifungal }\end{array}$ & (19) \\
\hline 5 & $\begin{array}{l}\text { Zataria } \\
\text { multiflora }\end{array}$ & Darab, Fars, Iran & $\begin{array}{l}\text { Thymol (37.88\%), Carvacrol } \\
(27.16 \%)\end{array}$ & $\begin{array}{c}\text { stimulates innate immunity, antibacterial and } \\
\text { antifungal activities, antiseptic, analgesic, and } \\
\text { carminative }\end{array}$ & (20) \\
\hline 6 & $\begin{array}{l}\text { Carum copti- } \\
\text { cum }\end{array}$ & Kazereun, Fars, Iran & $\begin{array}{l}\text { Thymol (36.7\%), } \gamma \text { - terpinene } \\
\text { (36.5\%), p-cymene }(21.1 \%)\end{array}$ & $\begin{array}{l}\text { diuretic, carminative, analgesic, anti-dyspnea and } \\
\text { anti-inflammatory, antiseptic }\end{array}$ & (21) \\
\hline 7 & $\begin{array}{c}\text { Salvia } \\
\text { mirzayanii }\end{array}$ & $\begin{array}{l}\text { Bandar Abbas, Hor- } \\
\text { mozgan, Iran }\end{array}$ & $\begin{array}{l}\text { Cineol }(41.20 \%) \text {, linalyl } \\
\quad \text { acetate }(10.72 \%)\end{array}$ & $\begin{array}{l}\text { Antibacterial, free radical scavenging, antioxi- } \\
\text { dant, neuroprotective }\end{array}$ & (22) \\
\hline
\end{tabular}


recommended by the European Pharmacopoeia (23). The extracted EO samples were dried over anhydrous sodium sulphate and stored in sealed vials at low temperature $\left(4^{\circ} \mathrm{C}\right)$.

\subsection{GC and GC/MS Analysis}

The analysis of EOs was performed using a Thermoquest-Finnigan Trace GC-MS instrument equipped with a DB-5 fused silica capillary column (60 $\mathrm{m} \times 0.25 \mathrm{~mm}$ i.d., film thickness $0.25 \mathrm{~mm}$ ). The oven temperature was programmed to increase from 60 to $250^{\circ} \mathrm{C}$ at a rate of $4^{\circ} \mathrm{C}$ per minute and finally held for $10 \mathrm{~min}$; transfer line temperature was $250^{\circ} \mathrm{C}$. Helium was used as the carrier gas at a flow rate of $1.1 \mathrm{~mL} / \mathrm{min}$ with a split ratio of $1 / 50$. The quadrupole mass spectrometer was scanned over the 35-465 amu (atomic mass units) with an ionizing voltage of 70 $\mathrm{eV}$ and an ionization current of $150 \mathrm{~mA}$. The GC/FID analysis of the oils was conducted using a Thermoquest-Finnigan instrument equipped with a DB- 5 fused silica column ( $60 \mathrm{~m} \times 0.25 \mathrm{~mm}$ i.d., film thickness $0.25 \mathrm{~mm}$ ). Nitrogen was used as the carrier gas at the constant flow rate of 1.1 $\mathrm{mL} / \mathrm{min}$; the split ratio was the same as that used for $\mathrm{GC} /$ MS. The oven temperature was raised from 60 to $250^{\circ} \mathrm{C}$ at a rate of $4^{\circ} \mathrm{C}$ per min and held for 10 minutes. The injector and detector (FID) temperatures were kept at 250 and $280^{\circ} \mathrm{C}$, respectively. Semi-quantitative data was obtained from FID area percentages without using correction factors.

\subsection{Identification of Essential Oil Components}

Retention indices (RI) were calculated using retention times of n-alkanes (C6-C24) that were injected after the oil at the same temperature and conditions. The compounds were identified by comparison of their RI with those reported in the literature (24) and their mass spectrum was compared with the Wiley Library.

\subsection{Determination of Antimicrobial Activities}

\subsubsection{Microorganisms}

The antimicrobial activities of the EOs against some oral pathogens including standard species of $S$. mutants (ATCC 35668), S. sanguis (ATCC 10556), S. salivarius (ATCC 9222 ), S. sobrinus (ATCC 27607), E. faecalis (ATCC11700), S. aureus (ATCC 25923, 29213 and ATCC 700698), C. albicans (ATCC 10261), C. dubliniensis (CBS 8501), C. tropicalis (ATCC 750), C. krusei (ATCC 6258) and C. glabrata (ATCC 90030) and four clinical isolates of $S$. mutants were determined in this study.

\subsubsection{Determination of Minimum Inhibitory Concentra-} tion

Minimum Inhibitory Concentrations (MICs) were determined using broth microdilution method rec- ommended by the CLSI with some modifications (25, 26). Briefly, for determination of antifungal activities against yeasts, serial dilutions of the EOs (0.015 to 16.0 $\mu \mathrm{L} / \mathrm{mL}$ ) were prepared in 96-well microtiterplates using RPMI-1640 media (Sigma, St. Louis, USA) buffered with MOPS (Sigma, St. Louis, The USA). To determine the antibacterial activities, serial dilutions of the EOs (0.062 to $32.0 \mu \mathrm{L} / \mathrm{mL}$ ) were prepared in Muller-Hinton Broth media (Merck, Darmstadt, Germany). Test fungi or bacteria strains were suspended in the media and the cell densities were adjusted to 0.5 McFarland standards at $530 \mathrm{~nm}$ wavelength using a spectrophotometric method (this yields stock suspension of $1-5 \times 10^{6}$ cells $/ \mathrm{mL}$ for yeast and $1-1.5 \times 10^{8}$ cells/mL for bacteria). $100 \mu \mathrm{L}$ of the working inoculums was added to the microtiter plates and the plates (treated wells and untreated controls) were incubated in a humid atmosphere at $30^{\circ} \mathrm{C}$ for 24 48 hours (fungi) or at $37^{\circ} \mathrm{C}$ for 24 hours (bacteria). 200 $\mu \mathrm{L}$ of the uninoculated medium was included as a sterility control (blank). In addition, growth controls (medium with inoculums but without essential oil) were included.

The growth in each well was compared with that of the growth control well. MICs were visually determined and defined as the lowest concentration of the essential oil producing no visible growth. Each experiment was performed in triplicate. In addition, media from wells with fungi showing no visible growth were further cultured on Sabouraud Dextrose Agar (Merck, Darmstadt, Germany) and from wells with bacteria showing no visible growth on Muller-Hinton agar (Merck, Darmstadt, Germany) to determine the minimum microbicidalconcentration (MMC). MMCs were determined as the lowest concentration yielding no more than four colonies, which corresponds to a mortality of $99.9 \%$ of the microbes in the initial inoculums.

\section{Results}

The antibacterial activities of the EOs against the common causes of oral infections are shown in Table 2. The EOs inhibited the growth of examined bacteria at concentrations of $0.062-4 \mu \mathrm{L} / \mathrm{mL}$, except E. faecalis, which was inhibited at concentration of 0.125-16 $\mu \mathrm{L} /$ mL. Furthermore, all of the EOs exhibited the minimal microbicidal activity (MMC) for the tested bacteria at concentrations ranging from 0.25 to $16 \mu \mathrm{L} / \mathrm{mL}$, except EO A. sieberi, which showed bactericidal activities at the range of $1-32 \mu \mathrm{L} / \mathrm{mL}$. Of the tested bacteria, E. faecalis had the highest MICs and MBCs. For the standard yeasts tested, the MICs for the EOs were in the range of 0.015-2 $\mu \mathrm{L} / \mathrm{mL}$ (Table 2). All the tested Candida spp. were killed by the EOs at about the same or twice the concentration of their corresponding MICs. Of the examined EOs, $S$. khuzestanica, Z. multiflora and S. bachtiarica showed the highest antimicrobial activities, respectively, while $A$. sieberi exhibited the lowest antimicrobial properties. 
Zomorodian Ket al.

Table 2. Antimicrobial Activity (Minimum Inhibitory Concentration, MIC; Minimum Microbicidal Concentration, MMC) of the Essential Oils Against Oral Pathogens ${ }^{a, b}$

\begin{tabular}{|c|c|c|c|c|c|c|c|c|c|c|c|c|c|c|}
\hline & $\mathbf{1}$ & & 2 & & 3 & & 4 & & 5 & & 6 & & 7 & \\
\hline Microorganisms & MIC & MMC & MIC & MMC & MIC & MMC & MIC & MMC & MIC & MMC & MIC & MMC & MIC & MMC \\
\hline Streptococcus mutants ATCC 35668 & 0.062 & 0.125 & 0.25 & 0.5 & 0.5 & 1 & 2 & 4 & 0.25 & 0.5 & 0.5 & 1 & 0.062 & 1 \\
\hline S. mutants 1 & 0.125 & 0.25 & 0.5 & 0.5 & 1 & 4 & 2 & 4 & 0.5 & 1 & 0.5 & 1 & 0.125 & 1 \\
\hline S. mutants 2 & 0.25 & 0.5 & 0.5 & 1 & 0.5 & 1 & 1 & 2 & 0.25 & 0.25 & 1 & 2 & 0.062 & 1 \\
\hline S. mutants 3 & 0.25 & 0.5 & 0.5 & 1 & 0.5 & 1 & 1 & 4 & 0.25 & 0.5 & 0.5 & 2 & 0.062 & 1 \\
\hline S. mutants 4 & 0.125 & 0.25 & 0.5 & 0.5 & 0.25 & 1 & 0.5 & 1 & 0.125 & 0.25 & 0.5 & 1 & 0.062 & 1 \\
\hline S. sanguis ATCC 10556 & 0.125 & 0.25 & 0.5 & 1 & 0.25 & 0.5 & 1 & 2 & 0.25 & 0.5 & 0.25 & 1 & 0.125 & 1 \\
\hline S. salivarius ATCC 9222 & 0.125 & 0.25 & 0.25 & 0.5 & 0.5 & 1 & 4 & $>32$ & 0.125 & 0.125 & 0.25 & 0.5 & 0.5 & 4 \\
\hline S. sobrinus ATCC 27607 & 0.062 & 0.5 & 0.25 & 0.5 & 0.5 & 2 & 2 & 16 & 0.125 & 0.125 & 0.25 & 0.5 & 0.125 & 4 \\
\hline Enterococcus faecalis ATCC11700 & 0.125 & 0.5 & 0.5 & 2 & 1 & 4 & 16 & $>32$ & 0.5 & 1 & 2 & 8 & 0.25 & 16 \\
\hline S. aureus ATCC 25923 & 0.25 & 0.5 & 0.5 & 1 & 1 & 8 & 2 & 4 & 0.125 & 0.25 & 0.5 & 1 & 0.062 & 4 \\
\hline S. aureus ATCC 29213 & 0.125 & 0.25 & 0.25 & 0.5 & 1 & 8 & 2 & 4 & 0.125 & 0.5 & 1 & 2 & 0.125 & 2 \\
\hline S. aureus ATCC 700698 & 0.125 & 0.25 & 0.25 & 0.5 & 2 & 16 & 1 & 2 & 0.25 & 0.5 & 1 & 4 & 0.062 & 4 \\
\hline Candida albicans ATCC 10261 & 0.031 & 0.031 & 0.031 & 0.062 & 0.125 & 0.25 & 1 & 2 & 0.062 & 0.125 & 0.125 & 0.125 & 1 & 2 \\
\hline C. dubliniensisCBS 8501 & $<0.015$ & 0.031 & 0.062 & 0.125 & 0.125 & 0.125 & 2 & 4 & 0.062 & 0.125 & 0.125 & 0.125 & 0.5 & 2 \\
\hline C. glabrata ATCC 90030 & $<0.015$ & 0.031 & 0.031 & 0.125 & 0.062 & 0.125 & 1 & 2 & 0.062 & 0.125 & 0.031 & 0.062 & 0.25 & 0.5 \\
\hline C. tropicalis ATCC 750 & 0.062 & 0.125 & 0.125 & 0.25 & 0.25 & 1 & 2 & 4 & 0.25 & 1 & 0.25 & 0.5 & 0.25 & 1 \\
\hline C. krusei ATCC 6258 & 0.031 & 0.031 & 0.125 & 0.125 & 0.25 & 0.5 & 2 & 4 & 0.25 & 0.5 & 0.25 & 0.25 & 1 & 4 \\
\hline
\end{tabular}

a Abbreviations: MIC, Minimum Inhibitory Concentration; MMC, Minimum Microbicidal Concentration.

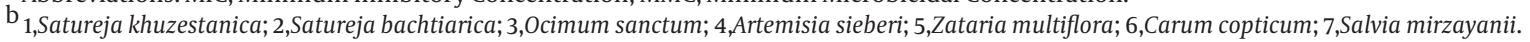

\section{Discussion}

Microbial flora accumulated on the mucosal and dental surfaces of the oral cavity are responsible for dental caries and biofilm formation (27). It has been reported that EOs are capable of inhibiting the growth of these $\mathrm{mi}-$ croorganisms and the formation of biofilms (28). These aromatic oils were used successfully in the management of recurrent aphthous stomatitis, plaque formation and gingivitis $(29,30)$. In this regard, lower potency of chlorhexidine in comparison to EOs has been reported previously(31). Organisms predominant in plaque formation and tooth decay are of the genus Streptococcus. Similar to the study of Adiguzel et al. (32), the growth of the standard and clinical isolates of the streptococci was inhibited by tested EOs at concentrations of 0.062 to $1 \mu \mathrm{L} /$ $\mathrm{mL}$, except EOs of A. sieberi, which exhibited higher MICs $(0.5-2 \mu \mathrm{L} / \mathrm{mL})$.

The ability of $S$. aureus to develop methicillin resistance is becoming a matter of great concern. MICs of the tested EOs against $S$. aureus were in the range of $0.06-2 \mu \mathrm{L} / \mathrm{mL}$, which is concordant with most previous studies $(33,34)$. In addition, EOs successfully inhibited the growth of $E$. faecalis recognized as the commonly isolated bacteria from endodontic infections $(8,9)$. These results are in agreement with the report of Sonboli et al. who showed significant antimicrobial activities of three Salvia species EOs against E. faecalis with MICs of $10 \mu \mathrm{L} / \mathrm{mL}$ (33). Candida spp. are another resident of the oral cavity associated with oral candidiasis and biofilm formation (10). Similar to the previous studies $(28,32,35)$, all of the EOs exhibited fungicidal activities against the standard species of Candida at concentrations ranged $<0.015-0.5 \mu \mathrm{L} / \mathrm{mL}$, except A. seiberi and S. mirzayanii which inhibited the growth of tested yeasts at concentrations of $0.25-2 \mu \mathrm{L} / \mathrm{mL}$.

Hydrophobicity is one of the main characteristics of Eos, which enables their incorporation into the cell membrane (15). As shown in Table 1, S. khuzestanica, S. bachtiarica, Z. multiflora and C. copticum were rich in phenolic monoterpenes, including carvacrol and thymol. It has been shown that antimicrobial activity of these phenolic monoterpenes is due to hydroxyl groups at different positions around the phenolic ring through disruption of the cytoplasmic membrane and leakage of ions and ATP. Although no strong antibacterial activity was reported for terpinene as the second main constituent of C. copticum (15), this activity might be attributed to the high thymol concentration of this plant. p-Cymene is another major component identified in the EO of Carum copticum, which is a hydrophobic molecule and causes swelling of the cytoplasmic membrane (36). It is not an effective antibacterial when used alone $(37,38)$. However, in combination with other phenolic compounds such as thymol, it has shown a greater antimicrobial activity by 
incorporating cymene in the lipid bilayer of bacteria and facilitating transport of thymol across the cytoplasmic membrane (39).

EOs of 0 . sanctum, A. seiberi, and S. mirzayanii were rich in 1,8-cineol and exhibited strong antimicrobial activity against tested microbes. It has been shown previously that 1,8-cineol has significant antimicrobial activities alone or in combination with other monoterpenesor drugs. Of the tested EOs, S. mirzayanii had the highest 1,8-cineol concentration and the lowest MICs against Gram-positive cocci, which is in accordance to the results of above study (40). These results supported the idea of using EOs in mouthwashes and denture cleansers, since they show high efficacy in inhibiting microbial strains, even in the plantitic form. Furthermore, anti-inflammatory activity $(41,42)$ and pleasant odor and flavor of these EOs are additional advantages to their antimicrobial activities to be used as a mouth rinse and other oral hygienic products.

\section{Acknowledgements}

This study was part of the thesis of Pooria Ghadiri. The study was financially supported by Shiraz University of Medical Sciences (Grant No. 91-01-64-4579).

\section{Authors' Contributions}

Study concept and design: Kamiar Zomorodian, Mohammad Jamal Saharkhiz and Mohammad Reza Moein. Acquisition of data: Tahereh Golzar and Pooria Ghadiri. Analysis and interpretation of data: Farideh Bahrani, Keyvan Pakshir and Mohammad Mehdi Fani. Drafting of the manuscript: Kamiar Zomorodian, Pooria Ghadiri and Peiman Mehriar. Critical revision of the manuscript for important intellectual content: Peiman Mehriar. Administrative, technical and material support: Mohammad Mehdi Fani. Study supervision: Kamiar Zomorodian.

\section{References}

1. Marcenes W, Kassebaum NJ, Bernabe E, Flaxman A, Naghavi M, Lopez A, et al. Global burden of oral conditions in 1990-2010: a systematic analysis. J Dent Res. 2013;92(7):592-7.

2. Zaura E, Keijser BJ, Huse SM, Crielaard W. Defining the healthy "core microbiome" of oral microbial communities. BMC Microbiol. 2009;9:259.

3. Takahashi N, Nyvad B. The role of bacteria in the caries process: ecological perspectives. J Dent Res. 2011;90(3):294-303.

4. MacFarlane TW, Helnarska SJ. The microbiology of angular cheilitis. Br Dent J.1976;140(12):403-6.

5. Goldberg MH. Infections of the salivary glands. In: Topazian RG, Goldberg MH editors. Management of infections in the oral and maxillofacial regions.. Saunders: Philadelphia; 1981.

6. Smith AJ, Jackson MS, Bagg J. The ecology of Staphylococcus species in the oral cavity. J Med Microbiol. 2001;50(11):940-6.

7. Bagg J, Sweeney MP, Wood K, Wiggins A. Possible Role of Staphylococcus aureus in Severe Oral Mucositis among Elderly Dehydrated Patients. Microb Ecol Health Dis. 1995;8(2):51-6.

8. Siqueira JJ, Rocas IN, Souto R, de Uzeda M, Colombo AP. Actinomyces species, streptococci, and Enterococcus faecalis in primary root canal infections. J Endod.2002;28(3):168-72.

9. Kayaoglu G, Orstavik D. Virulence factors of Enterococcus fae- calis: relationship to endodontic disease. Crit Rev Oral Biol Med. 2004;15(5):308-20.

10. Akpan A, Morgan R. Oral candidiasis. Postgrad Med J. 2002;78(922):455-9.

11. Hidron AI, Edwards JR, Patel J, Horan TC, Sievert DM, Pollock DA et al. NHSN annual update: antimicrobial-resistant pathogens associated with healthcare-associated infections: annual summary of data reported to the National Healthcare Safety Network at the Centers for Disease Control and Prevention, 2006-2007. Infect Control Hosp Epidemiol. 2008;29(11):996-1011.

12. Sweeney LC, Dave J, Chambers PA, Heritage J. Antibiotic resistance in general dental practice-a cause for concern? J Antimicrob Chemother. 2004;53(4):567-76.

13. Zomorodian K, Rahimi MJ, Pakshir K, Motamedi M, Ghiasi MR, Rezashah H. Determination of antifungal susceptibility patterns among the clinical isolates of Candida species. J Glob Infect Dis. 2011;3(4):357-60.

14. Tajkarimi MM, Ibrahim SA, Cliver DO. Antimicrobial herb and spice compounds in food. Food Control.2010;21(9):1199-218.

15. Burt S. Essential oils: their antibacterial properties and potential applications in foods--a review. Int J Food Microbiol. 2004;94(3):223-53.

16. Hur MH, Park J, Maddock-Jennings W, Kim DO, Lee MS. Reduction of mouth malodour and volatile sulphur compounds in intensive care patients using an essential oil mouthwash. Phytother Res. 2007;21(7):641-3.

17. Bezic N, Samanic I, Dunkic V, Besendorfer V, Puizina J. Essential oil composition and internal transcribed spacer (ITS) sequence variability of four South-Croatian Satureja species (Lamiaceae). Molecules. 2009;14(3):925-38.

18. Kumar A, Shukla R, Singh P, Dubey NK. Chemical composition, antifungal and antiaflatoxigenic activities of Ocimum sanctum L. essential oil and its safety assessment as plant based antimicrobial. Food Chem Toxicol. 2010;48(2):539-43.

19. Akavan Tafti A, Sahebjami M, Heydari M, Motallebnejad M. Evaluation top of form evaluation of the effects of Artemisia sieberi mouthwash $1 \%$ on denture stomatitis. Caps J Intern Med. 2010;1(2):47-9.

20. Motevasel M, Zomorodian K, Okhovat MA, Farshad S. A Study of the effect of zataria multiflora extract on methicillin resistant Staphylococcus aureus. Jundishapur J Microbiol. 2013;6(5).

21. Hejazian SH. Analgesic effect of essential oil (EO) from Carum copticum in mice. World J Med Sci. 2006;1:95-9.

22. Amirghofran Z, Bahmani M, Azadmehr A, Javidnia K, Ramazani M, Ziaei A. Effect of Salvia mirzayanii on the immune system and induction of apoptosis in peripheral blood lymphocytes. Nat Prod Res. 2010;24(6):500-8.

23. British pharmacopoeia.London: HMSO; 1988.

24. Adams RP. Identification of essential oil components by gas chromatography/mass spectrometry. 4th edVienna, Austria: Allured Publishing Corporation; 2007.

25. Clinical and Laboratory Standards Institute.. M7-A7 Methods for dilution antimicrobial susceptibility tests for bacteria that grow aerobically; Approved Standard.Wayne, PA: CLSI; 2006.

26. Clinical and Laboratory Standards Institute.. M27-A7 Reference Method for Broth Dilution Antifungal Susceptibility Testing of Yeasts; approved standard. . 2th edWayne, PA: CLSI; 2006.

27. Ebrahimi Saravi M, Vojdani M, Bahrani F. Evaluation of cellular toxicity of three denture base acrylic resins. J Dent (Tehran). 2012;9(4):180-8.

28. Saharkhiz MJ, Zomorodian K, Rezaei MR, Saadat F, Rahimi MJ. Influence of growth phase on the essential oil composition and antimicrobial activities of Satureja hortensis. Nat Prod Commun. 2011;6(8):1173-8.

29. Mansoori P, Hadji Akhoondi A, Ghavami R, Shafiei A. Clinical evaluation of Zataria multiflora essential oil mouthwash in the management of recurrent aphthous stomatitis. DARU J Pharm Sci. 2002;10(2):74-7.

30. Ciancio SG, Lauciello F, Shibly O, Vitello M, Mather M. The effect of an antiseptic mouthrinse on implant maintenance: plaque and peri-implant gingival tissues.J Periodontol.1995;66(11):962-5.

31. Shayegh S, Rasooli I, Taghizadeh M, Astaneh SD. Phytothera- 
peutic inhibition of supragingival dental plaque. Nat Prod Res. 2008;22(5):428-39.

32. Adiguzel A, Ozer H, Sokmen M, Gulluce M, Sokmen A, Kilic H, et al.Antimicrobial and antioxidant activity of the essential oil and methanol extract of Nepeta cataria. Pol J Microbiol. 2009;58(1):6976.

33. Sonboli A, Babakhani B, Mehrabian AR. Antimicrobial activity of six constituents of essential oil from Salvia. Z Naturforsch CJ Biosci. 2006;61(3-4):160-4.

34. Hammer KA, Carson CF, RileyTV. Antimicrobial activity of essential oils and other plant extracts. J Appl Microbiol.1999;86(6):985-90.

35. Sadeghi I, Yousefzadi M, Behmanesh M, Sharifi M, Moradi A. In vitro Cytotoxic and Antimicrobial Activity of Essential Oil From Satureja Intermedia. Iran Red Crescent Med J. 2013;15(1):70-4.

36. Ultee A, Bennik MH, Moezelaar R. The phenolic hydroxyl group of carvacrol is essential for action against the food-borne pathogen Bacillus cereus. Appl Environ Microbiol. 2002;68(4):1561-8.

37. Juven BJ, Kanner J, Schved F, Weisslowicz H. Factors that interact with the antibacterial action of thyme essential oil and its active constituents. J Appl Bacteriol. 1994;76(6):626-31.

38. Dorman HJ, Deans SG. Antimicrobial agents from plants: antibacterial activity of plant volatile oils. J Appl Microbiol. 2000;88(2):308-16.

39. Juliano C, Mattana A, Usai M. Composition and in vitro antimicrobial activity of the essential oil of Thymus herba-barona Loisel growing wild in Sardinia. J Essent Oil Res. 2000;12(4):516-22.

40. Mulyaningsih S, Sporer F, Zimmermann S, Reichling J, Wink M. Synergistic properties of the terpenoids aromadendrene and 1,8-cineole from the essential oil of Eucalyptus globulus against antibiotic-susceptible and antibiotic-resistant pathogens. Phytomedicine. 2010;17(13):1061-6.

41. Miguel MG. Antioxidant and anti-inflammatory activities of essential oils: a short review. Molecules. 2010;15(12):9252-87.

42. Hajhashemi V, Ghannadi A, Pezeshkian SK. Antinociceptive and anti-inflammatory effects of Satureja hortensis L. extracts and essential oil. J Ethnopharmacol. 2002;82(2-3):83-7. 